\title{
The Wild Pig (Sus scrofa) Behavior - A Retrospective Study
}

Boon Allwin ${ }^{1 *}$, Ranjni Swaminathan ${ }^{2}$, Anjana Mohanraj ${ }^{1}$, Gokkan Nishit Suhas ${ }^{1}$, Stalin Vedaminckam ${ }^{3}$, Sathish Gopal ${ }^{3}$ and Manoj Kumar ${ }^{4}$

${ }^{1}$ Madras Veterinary College, TANUVAS, Chennai, Tamil Nadu, India

2University of Copenhagen, Copenhagen, Denmark

${ }^{3}$ Department of Animal Husbandry, Government of Tamil Nadu, TANUVAS, Chennai, Tamil Nadu, India

${ }^{4}$ Forest College and Research Institute, Mettupalayam, TNAU, TANUVAS, Chennai, Tamil Nadu, India

*Corresponding author: Boon Allwin, Madras Veterinary College, TANUVAS, Chennai, Tamil Nadu, India, Tel: +914425304000; E-mail: boonallwin@gmail.com

Rec date: Dec 22, 2015; Acc date: May 10, 2016; Pub date: May 12, 2016

Copyright: ( 2016 Allwin B, et al. This is an open-access article distributed under the terms of the Creative Commons Attribution License, which permits unrestricted use, distribution, and reproduction in any medium, provided the original author and source are credited.

\begin{abstract}
Wild pigs are the most prolific, very intelligent and secretive species that over the recent past has been in a lot of conflict terms with the humans. These animals are adaptive generalists and survive in wide range of habitats worldwide. The reproductive traits of wild pigs are extraordinary showing high prolificacy so it becomes impossible to control their population. These animals have adapted to become nocturnal proving it difficult to know about their behavior. However in order in spite of these challenges the main objectives of this study was to understand the behavior and ecology of this particular species to come up the control strategies. Thus basis for documenting and understanding the wild pig behavior has dramatically evolved, contributing significantly to our understanding of these animals. In general, however, the lack of intensive field studies was attributed to the fact that wild pigs were regarded everywhere as a pest. The wild pig groups usually known as sounder's were tracked and all findings were documented. The study period was about a year and the wild pigs were tracked and observed at the adjoining regions of the Eastern Ghats (Sathyamangalam region) and the Western Ghats (Mudumalai tiger reserve, Anaimalai tiger reserve) and of Tamil Nadu state during November, 2012 to October, 2014. A variety of behaviors were documented such as social unit organization, Habitat utilization, Daily activity patterns, Movement patterns, Modes of mobility, Home range, Male-male competition, Maternal behavior, Resting/loafing beds, Mannerism and attitudes, Vigilance behavior, Vocalizations, Wallowing, Rubbing, Symbiotic grooming behavior, Scent marking, Senses. At the end of the study we were able to precisely outlay the above the entire behavior attributes of wild pigs. These findings are necessary to understand the wild pigs and their vermin nature to combat crop raiding, eventually cutting down Human-Wild pig conflict, that will a more scientific method of conservation to avoid conflicts ending in tragic outcomes.
\end{abstract}

Keywords: Wild pigs; Landscape diversity; Animals; Piglets

\section{Introduction}

Wild pigs are very intelligent and secretive. These animals are adaptive ecological generalists, capable of exploiting a wide variety of geographic locations, habitats and forage resources further observed that wild pigs were more difficult to study than other ungulates because of their "intelligence, shyness and vigilance combined with an acute sense of smell and hearing" [1]. These animals are a forgotten link in Conflict, Crisis and Conservation and are often overlooked but the universal damage they cause is immense [2]. It is just an outlook that we are starring at a catastrophe the wild pigs.

In spite of these challenges, the basis for documenting and understanding the wild pig behavior has evolved dramatically, contributing significantly to our understanding of these animals. In general, however, the lack of intensive field studies was attributed to the fact that wild pigs were regarded everywhere as a pest and were therefore despised, ending in tragic outcomes like poisoning, hunting in way to end up the conflict. This drove these animals to adopt a nocturnal activity pattern and frequently seek shelter in heavy, dense cover, making behavioral studies difficult if not impossible to conduct [3]. In spite of those challenges, a number of behavioral studies of freeranging wild pigs have been completed since that time [4].
The purpose of this paper is to provide a precise overview of wild pig behavior. Several topical areas are focused on and addressed in this paper, with the intention of providing a basis for understanding wild pig behavior within the context of better managing these animals in control scenarios. Some behavioral variation does exist among the wild pigs of the three regions (Agricultural areas adjoining Mudumalai, Anaimalai, and Sathyamangalam) of study; however these will be treated as one in the following sections unless otherwise specified.

\section{Materials and Methods}

Behavioral study of wild pigs (Sus scrofa) carried out in areas adjoining the Eastern Ghats (Sathyamangalam region) and the Western Ghats (Mudumalai tiger reserve, Anaimalai tiger reserve) and of Tamil Nadu state during November, 2012 to October, 2014. The wild pigs were identified by their field signs, [5] and they were tracked by foot and always observed from a vantage point, keeping in mind the critical distance. All observations were taken by a single observer so as to avoid variations.

The different aspects of wild pig behavior have been categorized into the following groupings:

Social unit organization,

Habitat utilization, 
Daily activity patterns,

Movement patterns,

Modes of mobility,

Home range,

Male-male competition,

Maternal behavior,

Resting/loafing beds,

Mannerism and attitudes,

Vigilance behavior,

Vocalizations,

Wallowing,

Rubbing,

Symbiotic grooming behavior,

Scent marking,

Senses.

\section{Results and Discussion}

\section{Each of the aspects of wild pig behavior is discussed separately in the following sections}

Social unit organization: Although not as gregarious as other ungulates like Bovids, Cervids, wild pigs are by nature very social animals and exist in groups known as sounders. This statement is based on the fact that the species is typically found in groups composed of two or more individuals. Within wild pig populations, the basic social unit is the sow and her litter (i.e., the family group). Males are usually solitary and remain secluded except when participating in breeding groups; however, groups of two or more mature boars do occur together and have also been documented in this study [6-8]. The wild pigs in this study were categorized into eleven groupings as follows:

Single adults,

Adult groups,

Single sub adults,

Sub adult groups,

Groups of both adults and sub adults,

Basic family groups (one adult with piglets),

"Sounders" (groups of wild pigs),

Extended family groups (adults with both piglets and sub adults),

Single piglets,

Piglet groups, and

Sub adult and piglets groups.

Wild pig group sizes in this study varied greatly among populations, but typically were an average from 4 to 13 and range from 2 up to 30 or excess individuals coinciding with the findings of Eisenberg and Lockhart [9], Barrett [10]. Most of these sounders are composed of single or multiple family groups. Multiple family groups are organized around two or three reproductively mature highly-related sows and their litters. The size of these sounders in an area varies depending upon season, habitat, water availability, type of plantations and predation [4]. Diong reported that the sounder size reached a maximum during the peak farrowing season. Diong [11] also noted that wild pig populations with higher reproductive success form larger family groups. Very large groups (i.e., more than 100 animals) of wild pigs do occur that were in some phenomenon of transit as observed by Prater [1], Lekagul and McNeely [12]. Such groups could be occasionally being observed in situations of a concentrated attractant like food resources such as agricultural crops, waterholes during dry seasons. These oversized groups were typically only a temporary localized phenomena and do not persist beyond the immediate site of the attraction. It was further observed that their familial groups varied with the meteorological parameters as well.

Although solitary sightings can included either sex or any age class of wild pig, most are composed of mature boars. Most studies have reported that adult males make up from $80 \%$ to $90 \%$ of the solitary wild pig sightings [13-16]. Depending upon the sex and age of an animal, an individual may temporarily occupy any one of several of categories. Sows become solitary to prepare for and give birth to their young. Following the birth, a sow typically remains alone with her litter until around the time when weaning that usually occurs about three to four months of age of the young ones. After the litter is weaned, two or more sows usually associate and form a larger social unit. These multiple family groups remain more or less stable until breeding activity begins and boars join the sows. Dispersal of young from these groups is a passive process, occurring at about five to ten months of age or sometimes requires more time depending on the seasonal variation or the young animals form groups that are permanent to that particular sounder. It was also observed that females generally remained with the mother after weaning and that females formed new kin groups with their female siblings. Subsequent to their leaving the family group, boars apparently maintain a solitary existence except for participation in breeding activity. As mature boars get older, their tendency toward maintaining an isolated way of life became more pronounced. These findings were in concurrence with Crouch $[8,17]$.

Habitat utilization: The habitats of wild boar were as varied as their diet. Home range and activity change with season and the availability of food resources and they characterized as having low habitat specificity, they prove to be habitat generalists. However, some factors seem to be important for the density of animals. Wild pigs were found to be more abundant in dense forests and areas with high food and landscape diversity. When agricultural fields were available, wild pigs were most comfortable in the edge areas between forests and fields where they have easy access to both food and hiding places. This causes them to be in constant conflict terms with the humans, having deleterious effects as documented by Sodeikat and Pohlmeyer $[2,4,18]$. The protective advantage of the forest was essential for these animals and resting places and breeding nests were always located in areas of dense vegetation where they feel safe and are protected from bad weather. Climatic factors have a strong effect on the animals' distribution in an area, causing non uniformity in the distribution of animal groups and also on the availability of feed stuff. Factors that affect food availability, like harsh winter and drought making the soil hard, were especially important and animals moved away from these areas at such times. During cold days they choose their resting places on sun exposed slopes that were readily available in the study area and during hot dry days they were observed to seek the cool moist forests with an abundance of wallows as reported by Singer et al. [19] and 
Lemel et al. [20]. Moisture was very important as the ground is easier to root and scents are better picked up and wild pigs were much more active under moist conditions. Nest sites are always located in close proximity to water. Climate does seem to have some effect on densities of the animals. The primary influence of climate on wild pigs is working through vegetation and food availability. Food availability is the decisive factor influencing population increase and the availability of at least one high energy food seems important for the establishment of wild pigs. The variations in the meteorological parameters determines the vegetation and this regulates the wild pig population in that area, so crop raiding is dependent on climatic variations as recorded by Allwin et al. [2]. However, this only reflects its occurrence before farming became established and the landscape has changed a lot since then. Both cereals and potato fields could become potential food sources of wild pigs. Cultivated areas in areas adjoining the Western Ghats (Mudumalai tiger reserve, Anaimalai tiger reserve) and Eastern Ghats (Sathyamangalam region) are typically surrounded by outlying land of forest which is an ideal situation for boars to crop raid, leading to conflict terms with humans.

Daily activity patterns: The daily activity patterns of wild pigs varied by location, because human's nearly always and everywhere exercised influences on wild pig populations, it was difficult to regard them as either diurnal or nocturnal. Both Kurz and Marchinton [14], Wood and Brenneman [21] reported that wild pigs were largely diurnal. It was further observed that in relatively undisturbed areas, wild pigs seemed to trend toward diurnal activity. However, intense predation pressure or human activity during the day will drive pigs to become more nocturnal in their activity patterns. Populations of wild pigs have also been seen to be primarily nocturnal, lying up during the day in dense cover. Spitz [22], Lemel et al. [20], Pei [23] even noted that wild boar use sunset as an apparent cue for arousal which was very evident in this study as most of the sightings were noted after sunset. It was also observed that pigs moved greater distances away from both water sources and cover during the night. In general, wild pigs tended toward a seasonally driven activity pattern and wild pigs are typically diurnal during the, winter and spring months, with activity peaks in early morning and late afternoon and a reduction at midday. During the summer months, the diurnal activity was reduced and nocturnal activity was increased. This shift may be a behavioral means of these animals controlling their body temperature, due to the absence of sweat glands the essentiality to thermo-regulate. This pattern was more evident in males than in females. Wild pig tend to be almost exclusively nocturnal during summer, are most active on moonlit nights which was in agreement with the findings made by Hughes, McIlroy and Saillard, Waithman, Mersinger and Silvy [8,24-26]. Similarly, wild pigs elsewhere have been found to be significantly more active on moonlit nights than on dark nights. The daily activity patterns also vary between the sexes. Sows maintained a relatively constant activity for prolonged periods, while boars exhibit brief bursts of movement followed by a lengthy period of relative inactivity. The activity pattern of sows varied from the recorded normal during farrowing. Sows significantly reduced their daily movements approximately one month before farrowing and started getting acclimatized to the nests that they were in.

Movement patterns: The movements of wild pigs appeared to be characteristic of general wandering or drifting, but were restricted to a defined area over periods of time. This wandering or drifting type of movement behavior is probably in response to the following: food availability, population density, reproductive activity, quality and interspersion of habitat, season, climatic conditions, disturbance by humans and social organization. Wild pigs were observed to become nomadic in their search for alternative forage resource and intersexual differences in daily movements that were apparent, with males being consistently more mobile than sows. Immature pigs were also significantly more active than adults. Wild pigs generally did not move very far in response to minor disturbance, including infrequent intervention, and usually return to their home ranges shortly afterward. Mean daily movement was less after disturbance from human pressure $(0.5 \mathrm{~km})$ as compared to movement with no disturbance $(0.6 \mathrm{~km})$. However, these animals were found to move permanently to more remote locations, up to eight kilometers away, in response to intensive and prolonged disturbances. All animals stayed within their home range to find escape cover. After leaving these hiding places, the piglets were found to use well-known paths to join up with their family groups within a short time. The movement by wild pigs over time typically does not entail long distances. However, in some instances, such long-distance movement can be in response to a stimulus and wild pigs will continue to confine their travels to such defined trails, even when they cross wide, open areas. It was further noted that most wild pig trails followed the shortest possible route from one point of interest to another regardless of the topography or vegetation. Wild pigs even established and used trails that go straight up a steep hill to reach such locations which was in regard with the finding of Choquenot et al. [27] and Waithman [25]. Wild pigs also utilize the trails made by other large mammals like Gaur, deer, which were very common co inhabitants in the study area and also the manmade foot paths and unpaved secondary roads.

Modes of mobility: Locomotion in wild pigs follows the standard unguligrade cursorial diagonal pattern typical of the Artiodactyls. Further, wild pigs exhibited the three basic symmetric movement gaits (patterns of footfall) of ungulates including walking, trotting and galloping. In addition, the faster non-walking gaits visually include a "bouncing" trot, a "rocking" lope and a "steady/flat" flex-extension gallop or run. A wild pig that is walking will typically place its feet in a heel-to-toe pattern such that the hind prints often almost perfectly overlap the front prints. The footfalls also straddle the medial line of the path being traveled. When galloping, a wild pig will often place their footfalls in groups of four with a further distinct pairing of the front and rear pairs. These animals normally travelled at a rate of 3.5 to 5 kilometers per hour as recorded by Barrett [28]. However, wild pigs are sure-footed, rapid runners and can travel relatively fast over open ground, reaching speeds of up to 40-50 kilometers per hour [29-31]. It was also observed that these pigs, when alarmed, trotted and galloped approximately 4 kilometers in less than 20 minutes. On the contrary Spitz and Janeu [32] reported that movement slower than 1 kilometer per hour corresponded to feeding, wallowing, exploring and marking, while travel faster than 2 kilometers per hour included escaping, excursion and dispersal movements. In addition, given their cursorial capabilities and general body shape "running wedge", bio-mechanically streamlined wild pigs are able to maneuver at high speeds into and through seemingly almost impenetrable thickets and cover. Being quick-footed on the ground, larger wild pigs could also physically jump over barriers as high as one meter with ultimate ease. This ability was not as visually graceful as in other ungulates, but was no less successful in crossing such vertical impediments to travel. This can include wiremesh and solid fencing as well as other obstacles as reported by Rue, Nowak $[29,31]$. These animals were observed to jump/climb their way over trap walls up to approximately two meters in height and consistent athletes. Wild pigs were also known to be very good, strong swimmers [29,33-36]. 
Home range: Wild pigs exhibited a home range behavior, in that the movements of these animals are generally restricted to a defined area over an extended period of time. In general, wild pigs show a general trend toward sedentary habits; however, depending upon ecological conditions, these animals may roam about widely in search of better forage conditions [37]. In addition, periodic irregular shifts in home range occur within this species [21]. The home range size in wild pigs is variable. Typical home ranges in this species cover an area of about $10 \mathrm{~km}^{2}$ and varied from 1 to $9 \mathrm{~km}$ in length on a side [6,16]. However, home ranges as large as $154 \mathrm{~km}^{2}$ have been reported [38]. The home range size is determined by a mixture of factors including the absolute and spatial availability of food, water and escape cover, the animal's body weight, and the local density of pigs and the level human inhabitation tending to alter the activity of wild pigs. In the study area wild pigs inhabiting areas with poor food supplies have notably larger home ranges than those occupying forested environments or agricultural lands with ample forage resources. Home ranges in wild pigs typically increase in size from daily to seasonal, and then to aggregate annual areas utilized. In addition, the intense predator pressure causes wild pigs to decrease their home range in an attempt to avoid the predators. Boars have larger daily, seasonal and overall home ranges than sows in agreement with the findings of Choquenot et al. [27] and Gaston et al. [39]. Sterner [40] reported that home ranges for boars were 2.5 to 4 times larger than those for sows. There is also greater variation in the male home ranges compared to female home ranges. It was also noted that boars made excursions beyond their established home range boundaries and then return; sows typically do not exhibit this behavior. Home ranges of boars and sows also overlapped extensively between and within the sexes. However, Barrett [10] and Sparklin [41] reported that range overlap was higher within than between the sexes in wild pigs but essentially it was noted that males tend to wander more having larger home ranges and it was further noted that sows appear to reduce their home range approximately one month before farrowing. It is noteworthy to mention the findings Singer et al. [19] that sows can also significantly reduce their home ranges when nursing their young. It was observed that sows with young less than 3 weeks old rarely moved more than 0.5 $\mathrm{km}$ from their farrowing nest location which was much higher than distance recorded in this study $0.1 \mathrm{~km}$. The adult sows used a small portion of their home range from immediately before until approximately 2 weeks after farrowing. The shapes of a wild pig's home range has been described as ranging from being generally circular to elongate $[19,24,41]$ and are determined by the local terrain, floral/ habitat cover and available resources. The remarkable finding was the home ranges were circular and they were generally more circular in summer than in winter. There was a tendency for wild pig home ranges to be bordered by manmade or natural topographic features. The use of the area encompassed by the home range is localized or patchy, with the different parts of their home range being connected by a network of paths which are regularly used $[6,15,18,42]$. These network paths are very common in the study area as tea/crop plantations are provided with paths, these were utilized by the pigs to navigate a geographical area. One or more core areas, each approximately $<1 \mathrm{~km}^{2}$ in size, exist within a wild pig's home range. Core areas typically contain preferred resting areas. The core areas of males were more scattered within the entire range and less intensively used than those of female [43]. Family groups used well-defined core areas within the social unit's home range. These core areas were located in dense thickets and the seasonal variations have also been noted in the home range sizes for wild pigs; although these differences are not consistent and vary depending upon the same suit of factors that generally determine home range size. In general, seasonal home ranges for wild boar were smallest when food was abundant. The summer home ranges for wild pigs did not differ significantly from the winter ones. Wild pigs are generally not territorial. As noted previously, there is extensive range overlap both between and within the sexes. In general, no defense of an exclusive area by either sex over time is typically reported. There was an extensive range overlap among mature males in this study area. The one exception to this behavior might be a few uniquely dominant males $[11,19,41,44-46]$.

Male-male competition: Male wild pigs can be very aggressive toward one another. This intrasexual aggression among boars increases with age. Such interactions are typically, but not always, between two individual boars. The causes of fighting of these aggressive exchanges are primarily one of two things: typically, it is males competing for breeding opportunities with females; less often it can be competition for forage resources. This behavior occurs year-round, but is most frequent during the peak of breeding. Roaring and squealing are typically heard in association with this competition. These animals do not exhibit head-on fighting; only lateral fighting is seen within this species. This male-male fighting within $S$. scrofa has also been described by various authors $[10,15,47-49]$.

A behavioral sequence of male-male lateral fighting has been reported among wild pigs. Initially, the combatants approach each other from a frontal position, sometimes circling one another at this point. Occasionally this involves either one or both facing one another and pawing the ground. At this stage, the two boars can also grind their mouths, snap their jaws at the opponent and produce foamed saliva. The presence of foaming saliva continues throughout most of the balance of the combat. Threatening staccatos of woofs or grunts are uttered during these initial stages of the fight. Two animals then begin strutting shoulder to shoulder, in a stiff-legged parallel walk in the same direction. On each animal, the mid-dorsal bristles are vertically erect, their ears are erect or pricked, and their heads are held upward. During this portion of the sequence, the two males push laterally at each other. They may also engage in a brief wrestling/shoving match. This stage can further include rearing up on their hind legs and pushing, kicking and biting each other from the upright, standing position. One of the boars then moves 180 degrees into a facing position, reestablishing a shoulder to shoulder contact. The two males then begin aggressively shoving or applying pressure with the shoulders. They also attempt to strike blows with their tusks on the opponents shoulder to flanks. Biting at the fore leg, neck, and ears is also attempted at this time. Such biting is sometimes realized as a charge from the side, proceeding directly at the opponent. The fight continues until one of boars is overwhelmed and breaks off the contact and flees. The winner typically pursues the loser for a short distance before terminating the chase. Such fighting between males can be intense, with either or both combatants getting injured or possible even killed [50-52].

Maternal behavior: The behavior of mature sows in farrowing and caring for their young parallels that of their domestic counterparts. This summary encompasses the spectrum of maternal behavior from pre-parturition nest building through the weaning of the litter. Pregnant sows build farrowing nests within $24 \mathrm{~h}$ prior to giving birth to their litters actually an instinctual trigger. The primary function of this structure has been theorized as providing the neonates with protection from inclement weather conditions. The combined presence of the sow, the nest, and huddling behavior exhibited by piglets in farrowing nests has been shown to enable young piglets to survive very 
cold air temperatures. This would be especially important in locations where the peak farrowing period is during December to February. However, it has been reported that wild sows in captivity can lose their piglets during very cold weather $[53,54]$. These smaller females may even remain with the larger sows through the birth and the subsequent use of and later departure from the farrowing nest. The nest is used for a period of between one to five days following the birth of the litter. In addition, since these females make foraging trips away from their litters during the first week following the birth, the nest has also been suggested to serve as protective camouflage for hiding the newborn piglets from potential predators like leopards and tigers that co-exist in the study area that prey on wild pigs [55]. The characteristics of a wild pig farrowing nest are typically round to oval or oblong in shape (on average $175 \mathrm{~cm}$ long and $105 \mathrm{~cm}$ wide), built in an excavated depression, and normally, but not always, lined with leaves/bedding material. These structures can have a dome-like cover or roof up to 150 $\mathrm{cm}$ in height, this is especially observed in colder climates like the areas adjoining Mudumalai regions or they modified pre-existing covers. Nests are larger in habitats with less overhead cover and in colder climates. Larger sows built significantly longer and higher nests than their smaller counterparts. Nesting materials used are varied and consist of plant species that are readily available and gathered from within approximately $20 \mathrm{~m}$ of the nests. However, some sows will travel more than $50 \mathrm{~m}$ to collect the nesting materials. Larger, older sows were shown to travel significantly further to collect these materials for their nests than did smaller, younger sows. Farrowing nests can also be built immediately next to trees, logs, boulders or other natural structures for either shelter or protection. The location and cover associated with farrowing nests is variable. Mayer et al. [56] reported that nests were most often built in forested habitats on level terrain as documented in this study. Hanson and Karstad [42] stated that farrowing nests were located in shaded areas on high ground. It was found that farrowing nests were constructed in places with abundant plant cover, water nearby, and a warmer temperature than other locations nearby. Diong [11], Covacevich [57] and Imaizumi and Chabata [58] all described wild pig farrowing nests constructed in tall grassland habitats. As observed the sow would build nests in growing plantations over $60 \mathrm{~cm}$ in height if the fields were left undisturbed. The birth of the piglets takes place in the sow's farrowing nest. The sow exhibited restlessness or nervousness just prior to beginning to give birth to her litter. The sow may also crawl under or burrow into the bedding material in the nest at that time. The young are typically born with the sow lying on her side. However, some births can take place with the sow lying on her ventrum or even standing up. Farrowing in wild pigs can last for more than 2-8 hours, with approximately 15-20 minutes between the births of each neonate. Martys [54] reported that the average time required for the birth of a whole litter was 199 minutes. The overall duration of farrowing tended to increase with the age of the sow. Vigorous wagging of the sow's tail has been reported to precede the birth of each piglet. This interval increases with the birth of each piglet. The piglets can be born in either a cephalic or breech presentation. Wild piglets are precocial, being very active and standing within seconds or minutes after birth. After each piglet's birth, the sow may sit up or stand, possibly even moving around the farrowing area, or simply remain still in the nest. Shivering, shaking or trembling by the sow is also observed between the births corresponding to the intense contractions of the uterus, ultimately depleting calcium. With the exception of an infrequent individual grunt, the sow typically makes no sounds or vocalizations during farrowing. The umbilical cords are separated by either the young repeatedly struggling to reach the teats or the sow's movements when it stands up or turns down. The sow usually pays little attention to her neonates until the last one is born, which is the smallest in the entire litter usually called the "runt" in domestic pigs. The sow typically does not assist the neonates in their efforts to clean themselves of the remaining fetal membranes. After birth, the neonates begin to actively seek out the teats to begin suckling. Following completion of births, the sow may or may not consume the blood, fluids, or placental material left in the nest. If conducted, this behavior would collectively serve to avoid attracting predators to the nest, allow the sow to obtain important nutrients, and keep the nest clean $[15,53,54,59-61]$. Any piglet carcasses from either stillbirths or postnatal mortalities may also be eaten by the sow, sometimes just compensate the dehydration, cannibalism a commonly encountered phenomenon in domestic pigs. Unlike most ungulates, neonatal wild pigs do not follow the mother following birth. The piglets will stay within or immediately around the farrowing nest for the first 1-2 weeks of life. During that time, the sow will make periodic but infrequent foraging trips away from the nest. The sow would stay in close physical contact with her litter to keep them warm, as well as near the nest to protect them from potential predators. She will move the young with her snout to clear a space to lie down to nurse them. A particular aggression and extreme caution was observed during this period. Warning growls and threatening charges by nesting sows were observed. However, these sows would then lead their litters away from the human observer after a short period of time rather than trying to chase off the human. The same was true for sows which had litters of piglets either in nests or with them and were bayed by stray dogs. In all cases, the sow defended the piglets from the intruder coinciding with the findings made by Kurz [6]. The characteristics of nursing behavior in wild pigs were similar to that described in the domestic sow [62]. After lying in suitable space, the sow will invite the young to begin nursing through repeated mixed soft squeals and grunts. The piglets will then begin nursing on a specific teat selected during the first few days of life, seldom if ever drinking from other teats. After weeks, the sow will begin to lead the piglets away in a close group from the nest to forage. For a short time, she may return them to the nest to rest or nurse. Eventually, the family group will expand their foraging range progressively further away from the nest site. The sow would continue to lead and protect her litter through weaning and up to their dispersal away from the family group. The younger the litter was, the more ready the sow was to defend them. It was further understood that if a predator seizes a piglet out of an assemblage of two or more family groups, that intruder will potentially be attacked by all of the sows present which have young.

Resting beds: During periods of extended rest, wild pigs established and used sheltered bedding areas. This usually entailed the construction of resting beds. Loafing or resting beds were similar to but were less complex than farrowing nests. These beds were used by either adult and/or immature animals for resting. Frequently used by single animals, wild pigs can have up to 15 individuals in one bed. Wild pigs are "contact" animals at rest, trying to be in as close physical proximity with conspecifics in these beds as possible. Typically, wild pig loafing or resting beds are simply shallow depressions in the ground, which may or may not be lined with bedding material as observed by various authors $[42,53,56,60,63]$. The compositions of these beds vary considerably, depending upon the season and the location of the structure and also to its location. Most of these beds were not in the human visibility range. Similar to farrowing nests, beds were often made immediately adjacent to a protective structure varying from a large tree, log, rock, or overhanging cliff, caves. When available, shallow caves can also serve as sites for beds (Nichols). Occasionally, a 
loafing bed will be encountered in late winter, or early summer which will be lined with a large amount of plant material and leaves scattered throughout. Such cold-weather beds can consist of large piles of bedding material. Loafing or resting beds can be used more than once, with some individuals returning to use a specific bed repeated times. Once flushed from a bed, wild pigs may not return to them for some time $[25,50]$.

Mannerisms and attitudes: An individual wild pig's mood or momentary temperament can generally be determined by their physical posture or gait at any particular time. The different mannerisms and postures recorded for wild pigs include the following:

(i) Aggressive posture: Erect or bristling of the mane, ears cocked forward (even in animals with droop ears, although it is a little more difficult to discern), stiff-legged and jerky walk, open mouth, lowing roar.

(ii) Threatening gait: Typically follows the aggressive posture, the male will charge a short distance toward the opponent or threat, with an open or snapping mouth. A loud, deep, and rapid staccato of "woofwoof-woof" is heard during the charge. The threatening charge ends suddenly in a stiff legged stop just short of the target being intimidated.

(iii) Submissive posture: Head pointed downward or held low, facing slightly away from dominant animal. If the dominant animal persists in the threat, the subordinate animal will lie down on its abdomen with its head and neck flat on the ground. The dominant animal may walk toward and around the laying animal. The subordinate animal may be squealing throughout this interaction.

(iv) Vigilant posture: Facing directly at source of curiosity, head bobbing, entailing the animal lowering its head and then suddenly lifting it to an upright posture, looking directly at the source. Occasionally, the animal may look away during the point when the head is lowered. This bobbing sequence may be repeated several times until the animal identifies the source as a potentially threatening or non-threatening object. No vocalizations heard during this posture. A wild pig in the curiosity or alert posture may also exhibit erect bristles along the mid-dorsum.

(v) Play among juveniles: This activity can take a variety of forms. It often resembles the fighting that takes place between adult males [17]. Typically involves a fair amount of shoving and chasing between participants. Fradrich [15] described three types of play in young wild pigs including social play, solitary play and play with objects.

These findings coincided with recordings of Baber, Barrett, Beuerle, Graves, Briedermann [13,28,49,61,64].

Vigilance behavior: The group size in wild pigs appears to have an influence on vigilance behavior, visual scanning to detect for or enable the escape from predators. The common predators in the study area were wild dogs, tigers, leopards. Quenette and Gerard [65] documented the vigilance behavior of captive wild pigs at feeding points using films. The results showed that individual vigilance decreased with increasing group size. This behavioral variation was markedly different between solitary individuals and any of the group sizes. This observation was coinciding with the results of our study.

Vocalizations: A number of vocalizations have been identified for wild pigs since long. Descriptions of the seven different general types of vocalizations are presented in the following paragraphs. The information presented in these descriptions was based on the field observations during the study period in the study area of wild pigs, and referred with those reported in the literature:

(i) Loud woof(s) or grunt(s): This is probably the most common type of vocalization heard by people encountering wild pigs in the study area. This is because most of these encounters involve an unexpected confrontation between human and wild pig. These vocalizations were mostly placed in human habitations like common dustbins, agricultural fields and unpaved roads. In these situations, this vocalization functions as an alarm call given by a surprised animal. In group situations, this would warn the other members of the group to be alert and prepared to take flight from a potential threat. This can also be heard immediately before a cornered or startled pig charges a human as defensive response to stimuli. Loud woofs or grunts are also heard as aggressive vocalizations during male-male fighting. This vocalization can be made by any age or either sex. It is low-pitched, loud woof or grunt emitted once or several times in quick succession. The outcome (i.e., "flight or fight") of these encounters depends upon the age of the animal and the distance to the threat. This vocalization is also heard as a warning grunt or grunts by a sow to her piglets upon the mother detecting a threat. Typically, the piglets responded by either crouching motionless or flee, usually in the direction of the signaling adult. The alarmed sow would often grunt and run, still grunting, and would be followed by the rest of the group. It can also be heard as a series of loud rapid grunts when a new animal joins a group. SquealThis is typically a distress or submission vocalization made during both the intraspecific and interspecific interactions of wild pigs. This call can be made by any animal, but is more commonly heard among immature or subordinate individuals. This vocalization is a loud, highpitched piercing squeal repeated continuously until the threat ceases. Squealing most often functions in the establishment of dominance order and as a distress reaction to immediate danger. Mature males can also make low squeals when fighting other males or when courting a sow in estrous $[13,28,63]$. Soft or low-volume squealing can be made by animals displaced in competitive feeding interactions.

(ii) Roar or growl: This is a soft to loud, low-pitched lowing roar or groaning bellow that is heard during male-male interactions within breeding groups [28] and when intruders approach a sow and her litter in an occupied nest site [6]. It is therefore typically made by only mature males or females. In the first situation, this call would probably function as a threat signal to another animal during the establishment of dominance order between breeding males. In the latter instance, such a vocalization would function as a threat signal to an intruder or potential predator. This vocalization was observed after the "critical distance" was violated.

(iii) General contact grunting: This is type of vocalization is made by all the members of a group when these animals are out of visual contact with one another. It is a series of low-pitched, soft grunts that are repeated frequently or in some instances, almost continuously and this in turn is cascaded by the other animals that are at the visible range as a presence call was observed. It functions to maintain the group within vocal contact with each other, and therefore, to keep the group from becoming separated.

(iv) Low grunt: This vocalization consists of a single low-pitched grunt, which is made by one animal during the act of displacing another animal in a feeding situation. It is apparently an assertion of dominance to a competing animal, and is heard during feeding group interactions. This may also be exhibited as a short series of rapid low grunts when a competitor for food approaches too close. Mature males 
can emit low series of grunts when pursuing a sow either for courtship or mating.

(v) Nursing grunt(s): These soft rhythmic grunts, which are repeated in a rapid series, are made by nursing sows at the beginning of and during nursing of her litter of piglets. The same grunts have been reported in wild piglets and they respond to this call by starting to nurse after the sow assumes the nursing posture. The function would be to solicit the litter to begin and continue nursing. This vocalization is also used to coax very young piglets to leave the farrowing nest for the first time and follow the sow as recorded by Hafez et al. [59] and Graves [61].

(vi) Feeding solicitation grunt(s): These grunts are heard when the piglets which are trying to nurse from the sow, each of them competing for a teat to feed from. The vocalization consists of mixed series of rapid soft squeals and low grunts. In such a situation, the sow would immediately respond by lying down and beginning to nurse.

(vii) Teeth clacking or popping: Not truly a vocalization but an aggressive expression this sound is produced by tooth impacts primarily the canines, through rapidly champing of the jaws. Mostly heard among mature males during aggressive interactions, it can consist of either single or a few multiple mouth impacts. This functions as a warning or threat during aggressive encounters between conspecifics or against potential predators. These were relevant with the record made by Nichols [63], Barrett [28], Kurz [19] and Baber. In general, these consist of grunts, woofs, squeals, snarls, and snorts. Females and young ones are typically heard more often than the males $[15,63]$.

Wallowing: Wild pigs wallow in order to lower body temperature as they do not have sweat glands and as a protective physiological combat ectoparasites. Wild pigs use mud wallows year-round, with no seasonality of use [66]. However, wallows are used most frequently during the summer months when these sites are important to animals trying to behaviorally reduce their heat load and thermo-regulate as observed by Crouch [17]. In addition, wallowing would also function to immobilize ectoparasites, which could then be mechanically removed through rubbing against trees or posts after wallowing. Certain mud wallows are used over long periods of time. Other wallows were very temporary in nature, drying up after summer of use as reported by various authors $[9,15,50,66]$. Typically, wallows consisted of a shallow, muddy depression that is oval to oblong in shape and are 0.7-2.7 m long, 0.8-1.8 m wide and approximately $0.2 \mathrm{~m}$ deep. Some wallows were sufficiently large enough to be used concurrently by more than one animal. Mud wallows were found almost anywhere that the wild pigs can find a low wet spot. This can include both shaded and open habitats. For that reason, most wallows were located in or adjacent to water bodies. Unusual locations like deep ruts or low-lying spots in unpaved jeep trails, and within drainage ditches were also been observed. Wallows appear to normally be made in areas with over story vegetation present, but not in areas of dense understory cover. In areas where open water sources were not available, wild pigs would also drink at wallows in agreement with Stegeman [67]. Scent marking is also reported to done at and around wallows. As such, wallowing may also have a territorial function among males during the peak of breeding an increased incidence of wallowing by larger and older males was seen during the peak breeding season. The negative impact of wallowing in ponds or other water resources resulted in contamination and environmental degradation as observed by Corbet [68], Eisenberg and Lockhart [9] and FernándezLlario [69].
Rubbing: Wild pigs frequently rubbed up against either natural or manmade objects. On observation this function of this was to provide comfort, remove excess mud, remove hair and mechanically rid the body of ectoparasites. Rubs involved almost any upright sturdy object, including trees, pines or hardwoods, telephone poles, fence and sign posts, rocks and boulders, and other manmade structures. In most cases there was an association between rubs and mud wallows, such that if a wallow existed, rubs would also be present in the immediate vicinity next to resting places and have been common to the entire "sounder". Wild pigs often suffer from substantial infestations of ticks and hog lice (Haematopinus suis). The combination of wallowing in mud and rubbing off that mud serves to immobilize and then mechanically remove these parasites. The tree rubs around mud wallows can vary in size from trees from 4 to $234 \mathrm{~cm}$ in the diameter at breast height. Isolated rubs on trees and poles or posts were not associated with wallows are also used. The rubbing behavior was observed at particular time of the day proving an essential conditioning of this behavior immediately after a wallow. As recorded by Stegeman [67] wild pigs chose objects of less than $15 \mathrm{~cm}$ in diameter for rubbing. In addition to medium- to large-sized pine trees wild pigs also rub on telephone poles and fence posts. Muddy, smoothly-rubbed bands on trees, poles, or posts are located between 10 and $94 \mathrm{~cm}$ above the ground, and often completely encircle the structure being rubbed. Wild pig rubs on trees as high as $140 \mathrm{~cm}$ have been observed. Bristles or guard hairs from this species are also frequently available in the mud or rough surface of structures being rubbed.

Symbiotic grooming behavior: Several species of birds have been reported to physically forage on or groom wild pigs for ectoparasites. These have variously included common crows (Corvus splendens), common mynahs (Acridotheres tristis), fan tails (Rhipidura sp) blackbilled magpies (Pica pica) all of them based on the geographical location and the season. This behavior had involved the wild pigs being groomed while either standing or lying down. In some instances, the standing wild pigs were moving about foraging with the birds "riding" on their backs. Some pigs even appeared to solicit such grooming, by walking over to the birds in question and then lying down on their sides and waiting for the birds to begin grooming. This symbiotic behavior has reportedly seen both in immature and mature wild pigs [9,70,71]. This type of grooming behavior also helps ectoparasitic control to aid ultimately in disease prevention curbing.

Scent marking: Wild pigs have and use a number of types of scent glands. The basic structure and function of the primary types of scent glands the metacarpal glands, preorbital glands, preputial gland, and tusk/lip glands are used by these animals are discussed in the following paragraphs. Metacarpal glands are a series of two to nine small but visible, shallow pores or pockets on the back part of the front feet. These glands are located in a line roughly parallel to the length of the forelimbs in the area overlying the posterior face of the metacarpal bones of the forefeet. The pores of the metacarpal glands are lined with different types of cells mostly apocrine tissue that produce or facilitate the movement of a chemical scent toward the gland's opening. These glands are found in both females and males. A bilateral asymmetry in females significantly larger on the right leg), and sexual dimorphism in size between males and females on the left limbs (i.e., males were larger). In addition, the glands were larger in sexually mature/ reproductively-active females. No seasonal variation is size is observed in the males as reported by Farnesi et al. [72], Heise-Pavlov et al. [73]. Bacchetta et al. [74] reported that males had more developed and functional glands than females, with the oldest males having the 
highest values of gland surface, gland thickness and tubule diameter Marking with the metacarpal glands is performed by the animal leaning forward and pawing the ground with the bottoms of its front feet this action is somewhat reminiscent of a house cat stretching forward and clawing at a carpet with its front paws. Boars mark with their metacarpal glands when they are participating in breeding groups or when they detect the presence of scent marking by another boar [75]. These glands play a relevant role in social communication by producing chemical signals involved in territorial definition as well as reproduction a pheromone mediated cascade. Because the size of these glands and the testes weights and testosterone serum levels were not correlated and the metacarpal glands were not involved in advertising dominance in males and that these glands are involved in a defensive behavior in reproductive females, but not in the identification of the mother by her piglets. The preorbital glands consist of a small secretory orifice located immediately in front of the eyes. The highest ranking sows in a matriarchal group of wild boars were found to use their preorbital glands to mark trees about 14 days before they come into heat to signal the presence of receptive females in the near future [76]. The preputial gland is an out pocket or blind sac diverticulum connected to the preputial area near the end of the penis. This gland is easily identified as the large swollen area near the distal end of the penis. Both urine and cells shed from the walls of the urine canal and prepuce collect in this blind sac. There are also large sebaceous and sweat glands surrounding the entrance of the diverticulum. The preputial fluid also contains a pheromone called "muskone" [10]. Collectively, all of this result in the production of the foul-smelling fluid that humans detect as the "boar odor" that is released whenever a mature male wild pig urinates upwind that is totally hormonal. It is also believed that the male pheromone that elicits the "mating stance" in females originates from the preputial gland. Boars either intentionally or inadvertently mark with this gland as a result of muscle contractions in the preputial area whenever they urinate. Such scent marking is also observed in conjunction with metacarpal gland marking, usually after the wild boar has marked the spot with its metacarpal glands. The tusk/lip glands are a scattered group of microscopic secretory glands found in the upper lip above the tusks or canine teeth in boars. Boars mark with these glands by rubbing their lips against an objector by chomping their jaws to produce foamed saliva which contains the scent. As a byproduct of contact, boars rub this scented saliva on sows during courtship or on rivals during fighting. Such saliva can also be left or marked on scent posts, including such objects as branches, tree trunks, or large leaves. The most infamous manner in which boars mark with these glands is when they "tusk" a tree (i.e., mark a tree with their tusk glands by rubbing the glands up and down against the tree, and inadvertently mar the tree with their canines). Tusking can vary from a single slash to trees that have a significant belt of bark on the trunk slashed away. Vigorous tusking can also result in a trench being created around the base of the tree by the boar doing the marking as observed in agreement with Graves [61]. Stegeman [67] reported that only pine trees were found to have been tusked by wild pigs which were observed in this study. Boars typically tend to tusk trees when in solitary situations and produce foamed saliva during social interactions. However, tusking trees can also be done by boars in mixed groups containing an estrous sow Tusking can also be associated with rubs Stegeman [67], Conley et al. [50], Diong [11]. Wild pigs also have proctoideal glands anatomically located at the entrance to the rectum, perineal glands located between anus and genital region, mandibular or mental glands consisting of numerous tubular glands in a swelling, marked by vibrissae, between the two halves of the jaw; reported to double in size during peak breeding, and rhinarial glands located in the midline of the upper part of the rhinarial disc. All of these secrete or produce odorous compounds, which may or may not function in scent marking [77].

Senses: Of the five primary senses, wild pigs tend to use four of these (i.e., smell, sight, hearing and touch) in their daily existence. These were documented when observing them in this study. These are briefly discussed in the following paragraphs:

Smell: Wild pigs excelled at the sense of smell. It has been estimated that when conditions are optimal, wild pigs could detect human scent downwind from a distance of 500 to 600 meters [33]. It also allowed these animals to detect the presence of fungi and other food resources buried below ground level upto 10 feet deep, that correlated with their rooting behavior. The olfactory region of the brain is extensive in correlation with the large size of the olfactory bulbs, Getty [77], Moulton [78], Shephard [79]. This enhanced sense often comes into play as means of finding food as well as avoiding enemies.

Sight: Wild pigs are presented with good, but not great eyesight. This species has a field of vision of approximately 245 to 260 degrees. They may also have a binocular field of vision covering a combined span of 30 to 50 degrees ahead of them. Wild pigs have been observed to recognize and flee from an approaching man or vehicle from more than $1.5 \mathrm{~km}$ away $[71,80]$.

Hearing: The sense of hearing seems to be the least developed of the senses among wild pigs. These animals seem to depend on this sense less than either smell or sight. The auditory sense in wild pigs appears to play its highest role in detecting the presence of other animals in thick cover. Hearing something, a wild pig will freeze or go into the alert posture until determining the nature or source of the sound detected. Conversely, this sense was useful for maintaining close proximity by groups in thick cover through use of the general contact grunting vocalizations.

Touch: Sense of touch within wild pigs is centered on the rhinarial pad and the mouth. In addition to housing a highly-developed olfactory organ, the nose, primarily the area around the rhinarial pad, encompasses a very receptive tactile sensory system. In this species, the cortical area of the brain associated with the snout is proportionately larger than in any other ungulate as reported by Moulton [78]. Not having manual dexterity in the form of a fingered hand, wild pigs use the rhinarial pad and mouth to "touch" or "pick up and feel" objects. Investigatory bites or chewing is not uncommon when pigs are presented with an object that is unknown to them accounting to a general exploratory behavior.

\section{Conclusion}

At the end of the study we were able to precisely outlay the above the entire behavior attributes of wild pigs. These findings are necessary to understand the wild pigs and their vermin nature to combat crop raiding, eventually cutting down Human-Wild pig conflict, that will a more scientific method of conservation to avoid conflicts ending in tragic outcomes. However, there are some practical short comings that were negotiated and every attempt to record the behavior of the wild pigs as such in the wild was made. Intensive studies relating to a selected group of individuals and the use of advanced techniques such as Radio- telemetry and GPS tracking may yield discrete conclusions. 


\section{References}

1. Prater SH (1965) The book of Indian animals. Bombay Natural History Society. Bombay, India.

2. Allwin B, Jayathangaraj MG, Palanivelrajan M, Raman M (2015) Enumerating endogenous faecal glucocorticoid metabolites as indicators of stress in wild pigs interfering with agriculture adjoining forest regions correlating with conflict and meteorological factors-A Noninvasive approach. International Journal of advanced Multidisciplinary Research 2: 63-76.

3. Dardaillon M (1988) Wild boar social groupings and their seasonal changes in Camargue, southern France. Zeitschrift fur Saugetierkunde 53: 22-30.

4. Fernández-Llario P (2004) Environmental correlates of nest site selection by wild boar Sus scrofa. Acta Theriologica 49: 383-392.

5. Allwin B, Jayathangaraj MG, Palanivelrajan M, Raman M (2015) Wild Pig Field Signs - Identity and Confirmation. International Journal of Life Sciences Research 3: 205-213.

6. Kurz JC (1971) A study of feral hog movements and ecology on the Savannah River Plant, South Carolina. MS Thesis, University of Georgia, Athens, Georgia.

7. Sweeney JM, Sweeney JR, Sweeney SW (2003) Feral hog, Sus scrofa. In: Feldhammer GA, Thompson BC, Chapman JA (Eds), Wild mammals of North America: Biology, management, and conservation. The Johns Hopkins Univ, Baltimore, Maryland, USA, pp: 1164-1179.

8. Hughes TW (1985) Home range, habitat utilization, and pig survival of feral swine on the Savannah River Plant. MS Thesis, Clemson University, Clemson, South Carolina, USA.

9. Eisenberg JF, Lockhart MC (1972) An ecological reconnaissance of Wilpattu National Park, Ceylon. Smithsonian Contributions to Zoology 101: 1-118.

10. Barrette C (1978) Fighting behavior of wild Sus scrofa. Journal of Mammalogy 67: 177-179.

11. Diong CH (1973) Studies of the Malaysian wild pig in Perak and Jahore Malayan Nature Journal 26: 120-151.

12. Lekagul B, McNeely JA (1988) Mammals of Thailand. 2nd edn. Saha Karn Bhaet Co, Bangkok, Thailand.

13. Baber DW (1977) Social organization and behavior in the feral hog. MS Thesis, Florida Institute of Technology, Melborne, Florida.

14. Kurz JC, Marchinton RL (1972) Radiotelemetry studies of feral hogs in South Carolina. Journal of Wildlife Management 36: 1240-1248.

15. Frädrich H (1974) A comparison of behavior in the Suidae. In: Geist V, Walther FR (Eds) The behavior of ungulates and its relation to management. International Union for the Conservation of Nature and Natural Resources, Morges, Switzerland, pp: 133-143.

16. Saunders G (1988) The ecology and management of feral pigs in New South Wales. MS Thesis, Macquarie University, Ryde, Australia.

17. Crouch LC (1983) Movements of and habitat utilization by feral hogs at the Savannah River Plant, South Carolina. MS Thesis, Clemson University, Clemson, South Carolina, USA.

18. Sodeikat G, Pohlmeyer K (2003) Escape movements of family groups of wild boar Sus scrofa influenced by drive hunts in Lower Saxony, Germany. Wildlife Biology 9: 43-49.

19. Singer FJ, Otto DK, Tipton AR, Hable CP (1981) Home range, movements and habitat use of European wild boar in Tennessee. Journal of Wildlife Management 45: 343-353.

20. Lemel J, Truve J, Soderberg B (2003) Variation in ranging and activity behavior of European wild boar Sus scrofa in Sweden. Wildlife Biology 9: 29-36.

21. Wood GW, Brenneman RE (1977) Research and management of feral hogs on Hobcaw Barony. In Wood GW (Ed) Research and management of wild hog populations. Belle Baruch Forest Science Institute of Clemson University, Georgetown, South Carolina pp: 23-35.

22. Spitz F (1986) Current state of knowledge of wild boar biology. Pig News and Information 7: 171-175.
23. Pei KJC (2006) Present status of the Formosan wild boar (Sus scrofa taivanus) in the Kenting National Park, southern Taiwan. Suiform Soundings 6: 9-10

24. McIlroy JC, Saillard RJ (1989) The effect of hunting with dogs on the numbers and movements of feral pigs, Sus scrofa, and the subsequent success of poisoning exercises in Namadgi National Park, ACT. Australian Wildlife Research 16: 353-363.

25. Waithman J (2001) Guide to hunting wild pigs in California. California Department of Fish and Game, Wildlife Programs Branch, Sacramento, California.

26. Mersinger RC, Silvy NJ (2007) Range size, habitat use, and dial activity of feral hogs on reclaimed surface-mined lands in east Texas. HumanWildlife Conflicts 1: 161-167.

27. Choquenot DJ, McIlroy, Korn T (1996) Managing vertebrate pests: Feral pigs. Bureau of Rural Sciences, Australian Government Publishing Service, Canberra, Australia.

28. Barrett RH (1971) Ecology of the feral hog in Tehama County, California. PhD Dissertation, University of California, Berkeley, California.

29. Rue LL (1968) Sportsman's guide to game animals: A field book to North American species. Outdoor Publishing, Lakeland, Florida.

30. Elman R (1974) The hunter's field guide to the game birds and animals of North America. Alfred A Knopf, New York.

31. Nowak RM (1999) Walker's mammals of the world. The Johns Hopkins University Press, Baltimore, Maryland 2: 1068-1071.

32. Spitz F, Janeau G (1990) Spatial strategies: An attempt to classify daily movements of wild boar. Acta Theriologica 35: 129-149.

33. Banoglu NA (1952) Turkey: A sportsman's paradise. The Press, Broadcasting, and Tourism Department, Ankara, Turkey.

34. Hennig R (1981) Schwarzwild: Biologie - Verhalten, Hege und Jagd. BVL Verlagsgesellschaft, München, West Germany.

35. Matschke GH, Hardister JP (1966) Movements of transplanted European wild boar in North Carolina and Tennessee. Proceedings of the Annual Conference of the Southeastern Association of Fish and Wildlife Agencies 20: 74-84.

36. Stephen D (1968) Encyclopedia of animals. St Martin's Press Inc., New York, USA.

37. Giles JR (1977) Control of feral pigs. Wool Technology and Sheep breeding 25: 29-31.

38. Maillard D, Fournier P (1995) Effects of shooting with hounds on size of resting range of wild boar (Sus scrofa L.) groups in mediterranean habitat. Journal of Mountain Ecology 3: 102-107.

39. Gaston W, Armstrong JB, Arjo W, Stribling HL (2008) Home range and habitat use of feral hogs (Sus scrofa) on Lowndes County WMA, Alabama. University of Nebraska-Lincoln, pp: 1-17.

40. Sterner JD (1990) Population characteristics, home range, and habitat use of feral pigs on Santa Cruz Island, California. MS Thesis, University of California at Berkeley, Berkeley, California.

41. Sparklin WD (2009) Territoriality and habitat selection of feral pigs on Fort Benning, Georgia, USA. MS Thesis, The University of Montana, Missoula, Montana.

42. Hanson RP, Karstad L (1959) Feral swine in the southeastern United States. Journal of Wildlife Management 23: 64-74.

43. Boitani L, Mattei L, Nonis D, Corsi F (1994) Spatial and activity patterns of wild boars in Tuscany, Italy. Journal of Mammalogy 75: 600-612.

44. Caley P (1993) Population dynamics of feral pigs (Sus scrofa) in a tropical riverine habitat complex. Wildlife Research 20: 625-636

45. Massei G, Genov PV, Staines BW, Gorman ML (1997) Factors influencing home range and activity of wild boar, Sus scrofa, in a mediterranean coastal area. Journal of Zoology 242: 411-423.

46. Saunders G, McLeod S (1999) Predicting home range size from the body mass or population densities of feral pigs, Sus scrofa (Artiodactyla: Suidae). Australian Journal of Ecology 24: 538-543.

47. De Poncins VE (1914) How wild boars fight. Journal of the Bombay Natural History Society 22: 791-793. 
48. Gundlach H (1968) Brutfursorge, Brutpflege Verhaltensontogenese und Tagesperiodik beim Europaischen Wildschwein (Sus scrofa L). Zeitschrift fur Tierpsychologie 25: 955-995.

49. Beuerle W (1975) Freilanduntersuchungen zum Kampf- und Sexualverhalten des Europaischen.

50. Conley RH, Henry VG, Matschke GH (1972) Final report for the European hog research project W-34. Tennessee Game and Fish Commission, Nashville, Tennessee.

51. Henry VG, Conley RH (1978) Survival and mortality of European wild hogs. Proceedings of the Annual Conference of the Southeastern Association of Fish \& Wildlife Agencies 32:93-99.

52. Goulding MJ (2003) Wild boar in Britain. Whittet Books, Ltd., Suffolk, United Kingdom.

53. Hediger H (1964) Wild animals in captivity: an Outline of the biology of zoological gardens. Dover Publications, Inc., New York.

54. Martys M (1982) Gehegebeobachtungen zur Geburts- und Reproduktionsbiologie des Europaischen Wildschweines (Sus scrofa L). Zeitschrift fur Saugetierkunde 47:100-113.

55. Allwin B, Vedamanickam S (2015) Phorate poisoning of a leopard (Panthera pardus) in the Nilgiris. Journal of toxicology and environmental health sciences 7: 1-3.

56. Mayer JJ, Martin FD, Brisbin IL (2002) Characteristics of wild pig farrowing nests and beds in the upper Coastal Plain of South Carolina. Applied Animal Behavior Science 78: 1-17.

57. Covacevich J (1976) A nest constructed by wild pigs. Victorian Naturalist 93: 25-27.

58. Imaizumi T, Chabata $\mathrm{T}$ (1977) Notes on the nest for reproduction of Ryukyu wild boar, Sus riukiuanus (in Japanese with English summary). Journal of the Mammalogical Society of Japan 7: 111-113.

59. Hafez ESE, Sumpton LJ, Jakway JS (1962) The behavior of swine. The Williams and Wilkins Company, Baltimore, Maryland pp: 334-369.

60. Bourlière F (1970) The natural history of mammals. Alfred A Knopf, New York.

61. Graves HB (1984) Behavior and ecology of wild and feral swine (Sus scrofa). Journal of Animal Science 58: 482-492.

62. Horrell I (1997) The characteristics of suckling in wild boar. Applied Animal Behavior Science 53: 271-277.

63. Nichols L (1962) Ecology of the wild pig, federal Aid in wildlife restoration final Report Project W-5-R-13. Hawaii Department of Land and Natural Resources, Division of Fish and Game, Honolulu, Hawaii.
64. Briedermann L (1986) Schwarzwild. VEB Deutscher Landwirtschaftsverlag, Berlin, Democratic Republic of Germany.

65. Quenette PY, Gerard JF (1992) From individual to collective vigilance in wild boar (Sus scrofa). Canadian Journal of Zoology 70: 1632-1635.

66. Belden RC, Pelton MR (1976) Wallows of the European wild hog in the mountains of east Tennessee. Journal of the Tennessee Academy of Sciences 51: 91-93.

67. Stegeman LJ (1938) The European wild boar in the Cherokee National Forest, Tennessee. Journal of Mammalogy 19: 279-290.

68. Corbet G (1966) The terrestrial mammals of Western Europe. Dufour Editions, Philadelphia, Pennsylvania.

69. Fernández-Llario PJ, Carranza, Hidalgo De Trucios SJ (1996) Social organization of the wild boar (Sus scrofa) in Donana National Park. Miscellania Zoologica (Barcelona), 19: 9-18.

70. Kilham L (1982) Cleaning/feeding symbioses of common crows with cattle and feral hogs. Journal of Field Ornithology 53: 275-276.

71. Massei G, Genov P (1995) Observations of black-billed magpie (Pica pica) and carrion crow (Corvus corone cornix) grooming wild boar (Sus scrofa). Journal of Zoology (London) 236: 338-341.

72. Farnesi RM, Vagnetti D, Tei S (1999) Morphological and ultrastructural study of carpal organ in adult female wild swine. Anatomia Histologia Embryologia 28: 31-37.

73. Heise-Pavlov S, Heise-Pavlov P, Bradley A (2005) Carpal glands in feral pigs (Sus domesticus) in tropical lowland rainforest in north-east Queensland, Australia. Journal of Zoology 266: 73-80.

74. Bacchetta R, Mantecca P, Lattuada L, Quaglia F, Vailati G, (2007) The carpal gland in wild swine: Functional evaluations. Italian Journal of Zoology 74: 7-12.

75. Mayer JJ, Brisbin IL (1991) Wild pigs in the United States: Their history, comparative morphology, and current status. The University of Georgia Press, Athens, Georgia.

76. Meynhardt H (1982) Schwarzwild-Report: Mein Leben unter Wildschweinen. Verlag J Neumann, Leipzig, East Germany.

77. Getty R (1975) Sisson and Grossman's the anatomy of the domestic animals. WB Saunders Company, Philadelphia, Pennsylvania.

78. Moulton DG (1967) Olfaction in mammals. Zoologist 7: 421-429.

79. Shepherd N (1994) Are You a Potential Potbellied Pig Parent.

80. Kramer RJ (1971) Hawaiian Land Mammals. Charles E Tuttle Company, Rutland, Vermont, USA. 